\title{
Physiological Aspects of Different Roller Skiing Techniques in Field Conditions
}

\author{
by \\ Michał Starczewski ${ }^{1}$ Piotr Żmijewski ${ }^{1}$, Katarzyna Witek², Andrzej Klusiewicz ${ }^{1}$
}

\begin{abstract}
The main goal of the study was to evaluate the impact of different roller skiing techniques (classical CT and skating ST) performed under field conditions on physical capacity variables in cross-country skiers. The second purpose was to evaluate the possibility to use the test results conducted under field and laboratory conditions interchangeably to determine training loads. Eight international-level cross-country skiers (4 male, 4 female) with $8.8 \pm 1.3$ years of skiing experience took part in the study. The athletes performed three graded tests to exhaustion: two under field conditions (roller skiing CT and ST techniques) and one in the laboratory: treadmill running (TR). All tests were conducted within a period of two weeks to compare general and specific physical capacity outcomes. ANOVA demonstrated significant differences in the threshold heart rate (HRAT4) (ST $175.3 \pm 10.8 \mathrm{bpm}, \mathrm{CT} 175.8 \pm 10.9 \mathrm{bpm}, \mathrm{TR} 181.5 \pm 11.1 \mathrm{bpm} ; p=$ 0.004), maximal oxygen uptake $\left(V O_{2 \max }\right)(S T 64.0 \pm 4.65 \mathrm{ml} / \mathrm{kg} / \mathrm{min}, C T 61.5 \pm 5.09 \mathrm{ml} / \mathrm{kg} / \mathrm{min}, T R 65.9 \pm 2.30$ $\mathrm{ml} / \mathrm{kg} / \mathrm{min} ; \mathrm{p}=0.008)$ and maximal HR (ST $189.3 \pm 10.9 \mathrm{bpm}$, CT $188.9 \pm 10.6 \mathrm{bpm}$, TR $199.5 \pm 10.3 \mathrm{bpm} ; \mathrm{p}=0.002)$. No significant differences were observed between classical and skating roller skiing techniques for maximal and threshold values except for threshold velocity (CT $13.4 \pm 1.11 \mathrm{~km} / \mathrm{h}$ vs. ST $14.7 \pm 1.17 \mathrm{~km} / \mathrm{h} p=0.002$ ). Maximal velocity was not measured. The main finding of the study is that it is possible to use threshold HR values obtained in roller skiing tests performed using the classical or skating techniques interchangeably to determine roller skiing training loads. The results of the study indicate that there is a need to verify maximal treadmill running exertion variables in specific roller skiing tests.
\end{abstract}

Key words: elite cross-country skiers, laboratory and field tests, roller skiing techniques, physiological response.

\section{Introduction}

Many studies have confirmed that crosscountry skiers have a high level of aerobic capacity, assessed using maximal oxygen uptake $\left(\mathrm{VO}_{2 \max }\right)$ (Holmberg and Rosdahl 2007; Sandbakk et al., 2016b; Tønnessen et al., 2015; Czuba et al., 2014; Vergès et al., 2003). In order to achieve optimal results, cross-country skiers need to train during the entire year. However, the training methods available depend on the weather conditions and the geographical location. These two factors determine in particular whether or not it is possible for the skiers to train on snow. If the skiers are unable to perform this kind of training in their home country, they frequently have to train abroad, which makes training highly expensive. In such situations, training on snow is often replaced by roller skiing, training on skiing ergometers, running exercise imitating crosscountry skiing, or running. All of these methods are aimed at increasing aerobic capacity, which is one of the main determinants of performance outcomes in cross-country skiing (Larsson et al., 2002; Mahood et al., 2001; Mikkola et al., 2010).

In order to select appropriate training loads, several variables at the anaerobic threshold (AT4) are used: heart rate (HRAT4), oxygen uptake ( $\left.\mathrm{VO}_{2 \mathrm{AT} 4}\right)$, pulmonary ventilation (VEAT4), as well as velocity during cross-country skiing, roller skiing, or running $\left(\mathrm{V}_{\mathrm{AT} 4}\right)$ or power (PAT4) during exercise

\footnotetext{
1 - Institute of Sport - National Research Institute in Warsaw, Department of Physiology, Poland.

2 - Jozef Pilsudski University of Physical Education in Warsaw, Department of Water and Winter Sports, Poland.
}

Authors submitted their contribution to the article to the editorial board.

Accepted for printing in the Journal of Human Kinetics vol. 66/2019 in March 2019. 
performed on a ski ergometer. In the literature (Hoffman et al., 1994; Holmberg et al., 2006; Klusiewicz and Cempa, 2011; Klusiewicz et al., 2011), results achieved in various types of exercise tests specific for cross-country skiing have been compared to each other; this includes roller skiing tests performed under field and laboratory conditions (on a treadmill), as well as arm ergometer tests. Many studies (Fabre et al., 2010; LaRoche et al., 2010; Stöggl et al., 2006) have found relationships between different types of tests and physical capacity in particular cross-country skiing techniques. Previously conducted research has assessed physical capacity variables during simulated cross-country skiing sprinting, roller skiing or skiing using the double poling technique (DP). It has been confirmed that there is a relationship between tests conducted under laboratory and field conditions (Larson, 2006; Mittelstadt et al., 1995; Wisløff and Helgerud, 1998; Zeni et al., 1996). The results obtained by various research groups indicate that it is possible to select a test which is optimal for determining physiological variables which are to be applied in training using the classical technique (CT) or the skating technique (ST).

The literature concerning the methodology of training cross-country skiers includes several studies which have compared roller skiing treadmill tests and ski ergometer tests with field tests performed using the ST (Forbes et al., 2010; Hoffman et al., 1995). Fewer reports are available with regard to cross-country skiing or roller skiing performed using the $\mathrm{CT}$ in field conditions, and they most frequently concern the measurement of physical capacity variables during DP (Doyon et al., 2001). Double poling engages a smaller number of muscle groups than the diagonal stride (DS), which involves using both the upper and lower limbs, and this has an impact on the values of the physiological variables achieved by the skiers. Lower values of maximal oxygen uptake in double poling than in the diagonal stride were reported by Sandbakk et al. (2016a, b), Doyon et al. (2001), and Watts et al. (1993). Those findings suggest that for comparison of physiological response during ST and CT roller skiing, diagonal stride technique or kick double pooling technique should be used. Hoffman et al. (1990) reported that oxygen cost of skating and kick double pole running was similar.

Although a considerable amount of research has been conducted regarding the physiological aspects of cross-country skiing, few authors have compared the skating and diagonal stride techniques during skiing. To the best of our knowledge, there have been no previous reports about the comparison of different roller skiing techniques under field conditions which are commonly used during summer preparations; thus, there is a gap in the scientific approach to the methodology of cross-country skiing training. In the light of the above, the main purpose of the current study was to evaluate the impact of roller skiing techniques measured under field conditions on physical capacity variables in cross-country skiers. Another goal of the study was to evaluate the possibility to use the results of the tests which were conducted under natural (CT and ST roller skiing) and laboratory (treadmill running) conditions interchangeably in determining training loads.

\section{Methods}

\section{Participants}

The participants of the study were elite Polish cross-country skiers (4 male skiers and 4 female skiers; members of the National Senior and U23 Teams), World Cups, World Championships or Olympic Games' participants. The mean age of the subjects was $20.5 \pm 2.0$ years (range 17.6-23.4 years), the women's mean height was $166.3 \pm 5.0$ $\mathrm{cm}$ and that of men was $175.8 \pm 6.6 \mathrm{~cm}$, mean body mass was $52.1 \pm 5.3 \mathrm{~kg}$ for women and $69.4 \pm 7.0 \mathrm{~kg}$ for men, and the subjects' skiing experience was 8.8 \pm 1.3 years. Measurements were done in the training period preceding the winter season. The athletes performed typical summer training for cross-country skiers during the study period. A substantial part of the weekly training plan was carried out on roller skis. Each of the subjects had a medical certificate confirming that they could perform high intensity exercise. Each subject gave written consent to participate in the study. For the participants under 18 years of age written parental consent was obtained. The participants were informed about the risks associated with taking part in the study and about the possibility to withdraw from the study at any moment. The study was approved by the local Research Ethics Committee, approval number KEBN-12-12-AK.

\section{Physical capacity assessment}

The athletes performed two types of 
graded tests: one in the laboratory on a treadmill and the other two under field conditions on roller skis. Both types of tests were conducted within a 2week period in order to compare the skiers' specific (roller skiing) and general (treadmill running) physical capacities. All the tests were performed in the morning, after a light breakfast, between 9.00 and $12.00 \mathrm{am}$. According to previous roller skiing testing procedures, protocols were designed on the inclined terrain to achieve maximal physical capacity values.

As for the roller skiing tests under field conditions, their performance was preceded with an individual warm-up lasting 20-30 minutes. The graded uphill ST and CT (self and terrain dependent diagonal stride or double pole kick technique) roller skiing tests were carried out to exhaustion, with a one-day break between them. On the first day the ST test and during the second day the CT test were conducted. Environmental conditions during the tests were similar on both days. On the first day, the temperature was $16.6 \pm$ $0.6^{\circ} \mathrm{C}$, humidity $89.1 \pm 2.0 \%$ and air pressure $895 \pm$ $1.5 \mathrm{hPa}$, while on the second day it was $15.7 \pm 1.6^{\circ} \mathrm{C}$, $86.6 \pm 4.5 \%$, and $899 \pm 5.5 \mathrm{hPa}$, respectively. The order of the tests was in accordance with the training programme of the National Team. It was assumed that in elite athletes, tests' order would not affect the results. During the tests performed using both techniques, the skiers individually adapted their running style to a particular velocity and inclination. The duration of the exercise bouts was 4 minutes, and 1-min breaks were taken for collecting blood samples. The criterion for selecting the intensity of the exercise was the velocity of roller skiing. The velocity of ST roller skiing in the first bout of exercise was $12 \mathrm{~km} / \mathrm{h}$, and it was increased by $2 \mathrm{~km} / \mathrm{h}$ both in female and male athletes in subsequent bouts. In the CT test, the velocity during the first exercise bout was $10 \mathrm{~km} / \mathrm{h}$ for women and $12 \mathrm{~km} / \mathrm{h}$ for men, and it was increased by $2 \mathrm{~km} / \mathrm{h}$ in each of the following bouts. A pacemaker cycled next to the subjects in order to make sure that they maintained a particular velocity during the $\mathrm{ST}$ and $\mathrm{CT}$ tests (Figure 1).

During the last (fourth) bout of the ST and $\mathrm{CT}$ tests, the skiers exercised with maximal intensity. As it was impossible for the subjects to maintain constant velocity in the last exercise bout, maximal velocity was not measured.

All the tests were performed on an asphalt surface with a varying inclination angle, which was $4 \%$ on average. During the tests performed using both the diagonal stride and skating techniques, the skiers wore SWENOR roller skis with standard resistance 2 wheels.

The treadmill running (TR) test included 5min bouts of exercise with an initial inclination of $1.5 \%$. Initial running velocity was $10 \mathrm{~km} / \mathrm{h}$ for women and $12 \mathrm{~km} / \mathrm{h}$ for men, and in subsequent exercise bouts, running velocity was increased by $2 \mathrm{~km} / \mathrm{h}$. In the fifth bout, a constant velocity (16 $\mathrm{km} / \mathrm{h}$ for women and $18 \mathrm{~km} / \mathrm{h}$ for men) was maintained, and the inclination was increased by $1.5 \%$ at the beginning of this bout and then every 2 minutes. The tests were performed to volitional exhaustion under standard laboratory conditions.

Based on the exercise tests, the anaerobic threshold (AT4) was determined for each subject for the blood lactate concentration of $4 \mathrm{mmol} / \mathrm{l}$ using the interpolation method. The threshold values of the $\mathrm{HR}, \mathrm{VE}, \mathrm{V}$ and $\mathrm{VO}_{2}$ for each test were determined.

Plasma blood lactate concentrations (BLa) were measured in the blood collected from the earlobe immediately after the subjects completed each bout of exercise. BLa concentrations were determined using a Dr. Lange LP400 photometer (Hach Lange Gmbh, Germany). During the tests, we continuously recorded the HR using a POLAR s710 heart rate monitor (Polar Electro Europe AG, Switzerland) and respiratory exchange variables in a breath-by-breath $(\mathrm{BxB})$ mode using a MetaMax 3B gas analyser (CORTEX Biophysik $\mathrm{GmbH}$, Germany). Before each test, the apparatus was calibrated (Mcfarlane et al., 2012). Vogler et al. (2010) reported validity and reliability of the MetaMax 3B in a group of elite athletes.

\section{Statistical analysis}

Tests for dependent samples were used in order to compare the values of exertion variables measured during the treadmill test and in field tests. The results were analysed using Friedman's non-parametric one-way analysis of variance (ANOVA), and post-hoc Dunn-Bonferroni tests were performed to verify the statistical significance of the differences between particular tests. Statistical significance was set at $p \leq 0.05$. All statistical analyses were carried out using STATISTICA 12 (StatSoft, Inc.; 2014). 


\section{Results}

ANOVA demonstrated significant differences in the selected physical capacity variabls for the three tests, that is the treadmill test and the field diagonal stride and skating roller skiing tests (Table 1). Significant differences were observed in anaerobic threshold velocity $\left(\mathrm{V}_{\mathrm{AT}}, p=0.002\right)$, threshold heart rate (HRAT4, $p=$ $0.004)$, threshold pulmonary ventilation (VEAT4, $p=$ $0.011)$, maximal heart rate $\left(\mathrm{HR}_{\max }, p=0.002\right)$, maximal oxygen uptake per kilogram of body mass $\left(\mathrm{VO}_{2 \mathrm{max} / \mathrm{kg},} p=0.008\right)$, and peak blood lactate concentration (BLamax, $p=0.016$ ).

\section{Table 1}

Analysis of variance for selected exertion variables describing cross-country skiers' physical capacity $(n=8)$.

\begin{tabular}{|c|c|c|c|c|c|}
\hline Variable & Test & Mean \pm SD & Minimum & Maximum & $p$ \\
\hline & Skating & $14.7 \pm 1.17$ & 12.9 & 16.4 & \\
\hline \multirow[t]{3}{*}{$\mathrm{V}_{\mathrm{AT} 4}(\mathrm{~km} / \mathrm{h})$} & Classical & $13.4 \pm 1.11$ & 12.1 & 15.2 & 0.002 \\
\hline & Treadmill running & $13.7 \pm 0.59$ & 12.7 & 14.4 & \\
\hline & Skating & $175.3 \pm 10.8$ & 156.0 & 194.0 & \\
\hline \multirow[t]{3}{*}{$\mathrm{HR}_{\mathrm{AT} 4}(\mathrm{bpm})$} & Classical & $175.8 \pm 10.9$ & 159.0 & 194.0 & 0.004 \\
\hline & Treadmill running & $181.5 \pm 11.1$ & 160.0 & 194.0 & \\
\hline & Skating & $56.0 \pm 4.27$ & 49.5 & 62.9 & \\
\hline \multirow[t]{3}{*}{$\mathrm{VO}_{2 \mathrm{AT} 4}(\mathrm{ml} / \mathrm{kg} / \mathrm{min})$} & Classical & $53.7 \pm 3.90$ & 48.1 & 60.2 & 0.093 \\
\hline & Treadmill running & $54.1 \pm 2.91$ & 51.4 & 60.0 & \\
\hline & Skating & $108.4 \pm 22.7$ & 78.0 & 142.0 & \\
\hline \multirow[t]{3}{*}{$\mathrm{VEAT}_{4}(1 / \mathrm{min})$} & Classical & $101.1 \pm 18.6$ & 84.0 & 131.0 & 0.011 \\
\hline & Treadmill running & $92.8 \pm 22.1$ & 69.0 & 123.0 & \\
\hline & Skating & $189.3 \pm 10.9$ & 169.0 & 207.0 & \\
\hline \multirow[t]{3}{*}{$\mathrm{HR}_{\max }(\mathrm{bpm})$} & Classical & $188.9 \pm 10.6$ & 170.0 & 203.0 & 0.002 \\
\hline & Treadmill running & $199.5 \pm 10.3$ & 181.0 & 211.0 & \\
\hline & Skating & $143.6 \pm 31.6$ & 105.0 & 190.0 & \\
\hline \multirow[t]{3}{*}{$V_{\max }(1 / \min )$} & Classical & $139.8 \pm 31.7$ & 105.0 & 183.0 & 0.159 \\
\hline & Treadmill running & $132.9 \pm 24.6$ & 105.0 & 173.0 & \\
\hline & Skating & $64.0 \pm 4.65$ & 56.3 & 68.6 & \\
\hline \multirow[t]{3}{*}{$\mathrm{VO}_{2 \max }(\mathrm{ml} / \mathrm{kg} / \mathrm{min})$} & Classical & $61.5 \pm 5.09$ & 51.8 & 67.3 & 0.008 \\
\hline & Treadmill running & $65.9 \pm 2.30$ & 60.5 & 67.6 & \\
\hline & Skating & $9.5 \pm 1.77$ & 7.5 & 12.7 & \\
\hline \multirow[t]{2}{*}{ BLamax (mmol/1) } & Classical & $10.0 \pm 2.00$ & 7.4 & 13.9 & 0.016 \\
\hline & Treadmill running & $13.3 \pm 2.48$ & 10.7 & 17.6 & \\
\hline
\end{tabular}




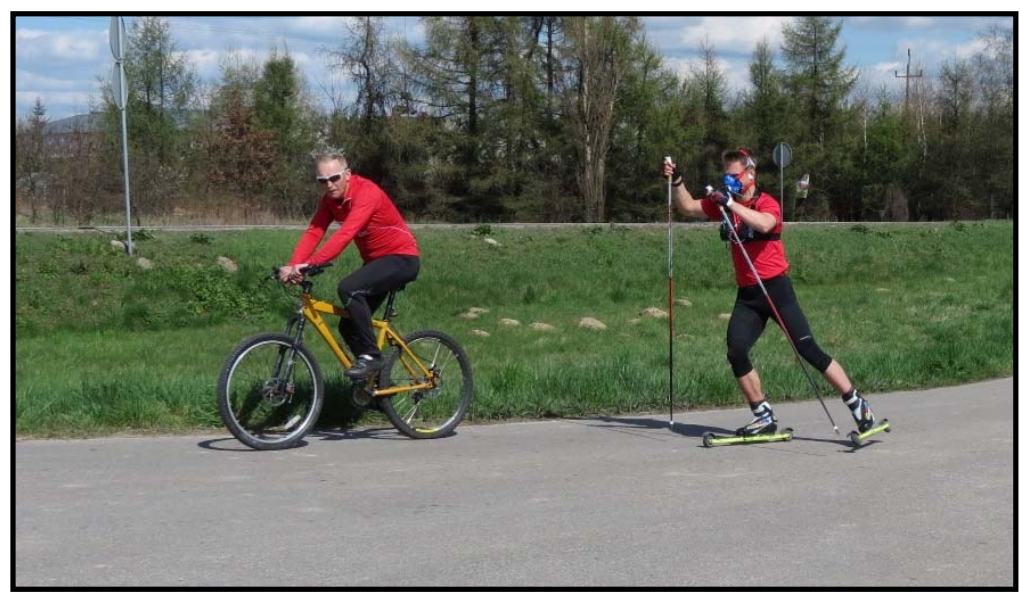

Figure 1

Graded skating roller skiing test performed at the velocity imposed by the pacemaker.

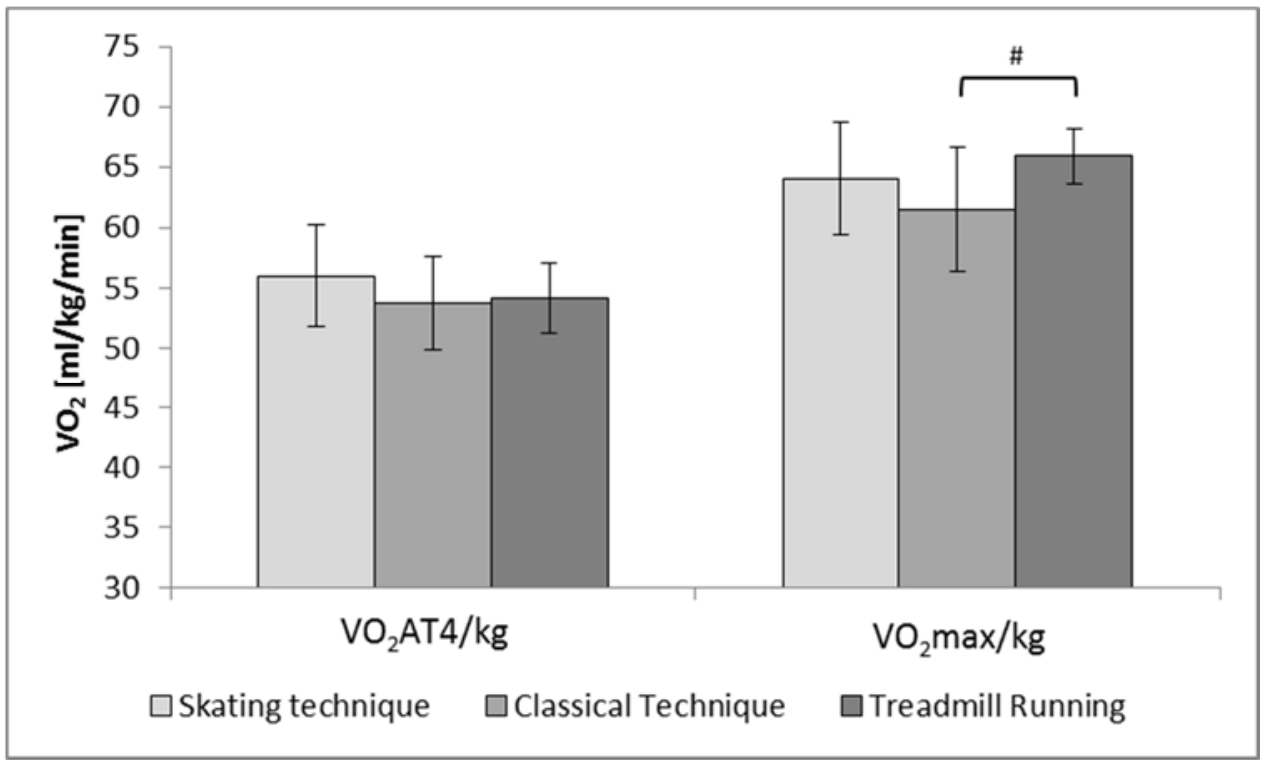

Figure 2

Post-hoc analysis of relative maximal (vo2max $/ \mathrm{kg})$ and threshold (vo2at4/kg) oxygen uptake values measured in the three types of tests in cross-country skiers $(n=8)$. \# - statistically significant difference between the classical technique and treadmill running tests $(p<0.05)$. 


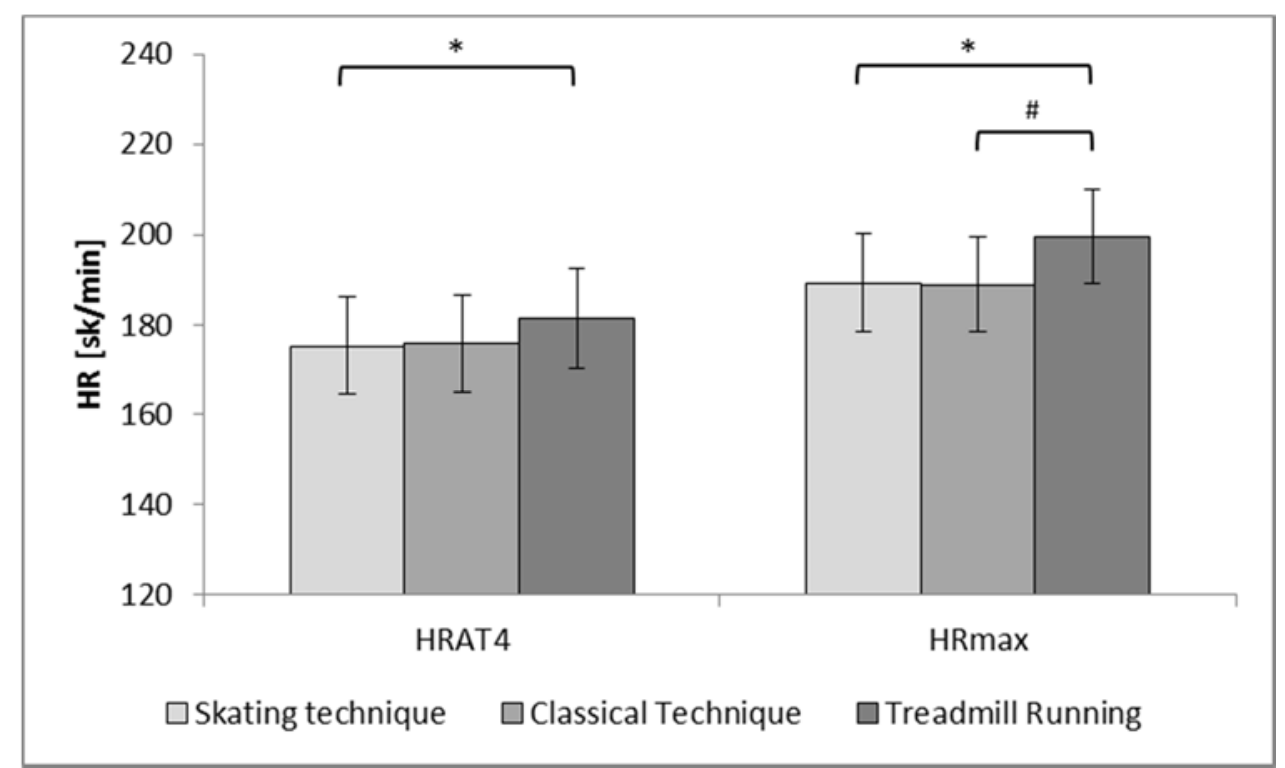

Figure 3

Post-hoc analysis of relative maximal $\left(\mathrm{hr}_{\max }\right)$ and threshold $(\mathrm{hrat})$ heart rate values measured in the three types of tests in cross-country skiers $(n=8)$.

\# - statistically significant difference between the classical technique and treadmill running tests $(p<0.05)$.

* - statistically significant difference between the skating technique and treadmill running tests $(p<0.05)$.

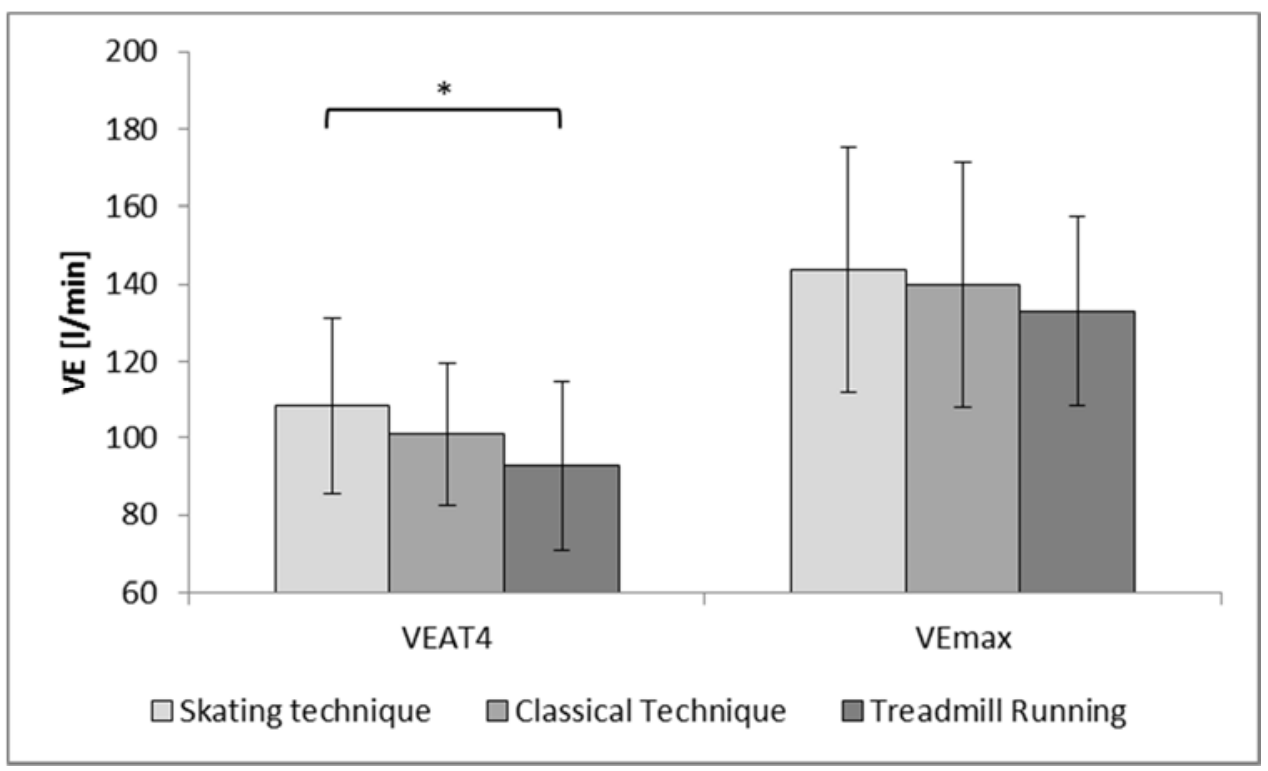

\section{Figure 4}

Post-hoc analysis of maximal (vemax) and threshold (veatt) pulmonary ventilation values measured in the three types of tests in cross-country skiers $(n=8)$.

* - statistically significant difference between the skating technique and treadmill running tests $(p<0.05)$. 


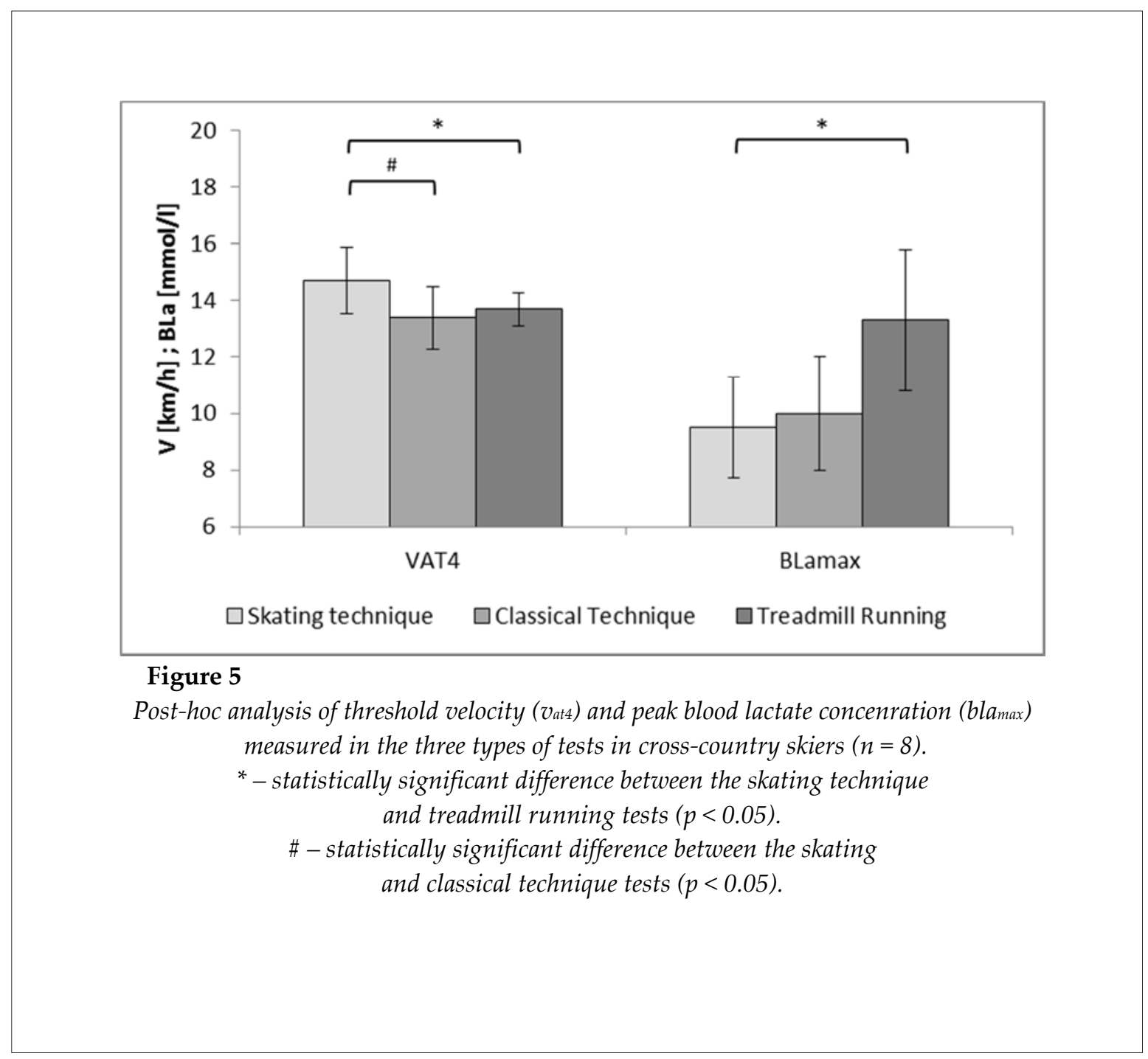

Threshold (AT4) and/or maximal (max) values are given for velocity $(\mathrm{V})$, heart rate $(\mathrm{HR})$, oxygen uptake $\left(\mathrm{VO}_{2}\right)$, pulmonary ventilation $(\mathrm{VE})$, and blood lactate concentration (BLa).

Post-hoc testing showed significant differences between relative maximal oxygen uptake $\left(\mathrm{VO}_{2 \max / \mathrm{kg}}\right)$ during the $\mathrm{CT}$ test compared to the TR test $(p=0.008)$, as shown in Figure 2. Despite

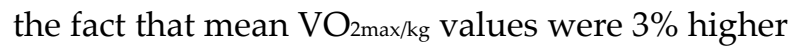
in the ST test than in the TR test, a non-significant trend in $\mathrm{VO}_{2 \max / \mathrm{kg}}$ values was observed between the tests $(p=0.073)$.

The post-hoc tests found significant differences in the threshold values for the heart rate (HRAT4) between the ST and TR tests $(p=0.012)$ (Figure 3). HR max achieved during TR was significantly different from that in the DS $(p=$ $0.008)$ and ST $(p=0.008)$ tests.
Maximal pulmonary ventilation (VEmax) did not differ significantly between the tests; however, significant differences were observed in VEAT4 between the ST and TR tests $(p=0.008)$, as illustrated in Figure 4.

$\mathrm{V}_{\text {AT4 }}$ was significantly different between the threshold velocity during the ST and DS roller skiing tests $(p=0.002)$ and between the ST and TR tests $(p=0.026)$. However, no differences were observed in VAT4 between the CT and TR roller skiing tests (Figure 5). Significant differences were also found in peak blood lactate concentration (BLamax) between the ST and TR tests $(p=0.026)$.

\section{Discussion}

The main aim of the study was to determine whether it was possible to use most of the threshold variables obtained following roller 
skiing tests performed using the classical or skating techniques in order to plan skiers' summer training programs. When threshold values for these techniques were compared, significant differences were found only for threshold velocity (VAT4), as shown in Figure 5. HRat4, VEaT4, and $\mathrm{VO}_{2 \mathrm{AT} 4 / \mathrm{kg}}$ did not differ between tests performed using the two techniques (Figures 2-4). Welde et al. (2003) observed similar relationships between HRAT4, VEAT4, and VO2AT4 threshold values in crosscountry skiing using the two techniques. Our findings confirmed that it was possible to carry out only one type of a roller skiing test, with the use of one of the two techniques (classical or skating), in order to determine training zones based on HR values. However, if one is to use threshold velocity, which is independent of the increase in the heart rate during prolonged exercise, the tests should be performed separately for each of the techniques (Figure 5).

The comparison of the maximal values of the physiological variables examined for the skating and classical roller skiing techniques also did not reveal significant differences $(\mathrm{HR}=189.3 \pm$ 10.9 vs. $188.9 \pm 10.6 \mathrm{bpm}, \mathrm{VE}=143.6 \pm 31.6$ vs. 139.8 $\pm 31.7 \mathrm{l} / \mathrm{min}, \mathrm{VO}_{2 \max }=64.0 \pm 4.65$ vs. $61.5 \pm 5.09$ $\mathrm{ml} / \mathrm{kg} / \mathrm{min}$, respectively), as illustrated in Figures 2-4. These data confirm that it is possible to use the classical and skating field tests interchangeably in order to assess the skiers' response to exercise at maximal intensity. On the other hand, in the TR test, significantly higher BLamax and HRmax were observed than in the ST and CT tests (Table 1, Figures 3 and 5). Previous research (Fabre et al., 2008; Myklebust et al., 2014; Welde et al., 2003) has also found $\mathrm{HR}_{\max }$ as well as $\mathrm{VO}_{2 \max }$ to be higher during TR compared to roller skiing tests. In the current study, a similar response in terms of higher maximal oxygen uptake during TR was found only in the CT test (Figure 2). Different results were obtained by Welde et al. ( 2003), who did not observe significant differences in maximal oxygen uptake during treadmill running compared to skiing using the diagonal stride technique. The discrepancies between the results reported in the literature and in the current study indicate a need to verify maximal treadmill running exertion variables using specific roller skiing tests.

Another finding was the lack of significant differences between threshold values in the treadmill running test and the roller skiing field test performed using the CT. Neither $\mathrm{VO}_{2 \mathrm{AT} 4}$ nor HRAT4 differed significantly between the two types of tests (Figures 2 and 3). Similar results were obtained by Welde et al. (2003) when comparing diagonal stride cross-country skiing with treadmill running. In a different study, Larson (2006) found lower values of HRAT4 during roller skiing using the double poling technique compared to treadmill running. The current study only found a nonsignificant trend $(p=0.053)$ towards lower HRAT4 values in the $\mathrm{CT}$ test compared to the TR test (Figure 3). These results would suggest that threshold heart rate values (HRAT4) from the TR test can be used in training cross-country skiers using $\mathrm{CT}$ roller skiing. However, it is worth noting that HRAT4 was approximately $3 \%$ lower during the CT test than during the treadmill running test. Therefore, it is recommended that athletes perform a field roller skiing test if they consider applying $H R$ values to training practice.

The comparison between threshold values obtained in the treadmill running test and the skating roller skiing field test showed that there were significant differences in the values of HRAT4, VEAT4, and VAT4 (Figures 3-5). The only exertion variable which did not differ between the two tests was oxygen uptake at the anaerobic threshold (Figure 2). Other authors have found no differences in HRAT4 and $\mathrm{VO}_{2 \mathrm{AT}}$; however, they did find significant differences in VEAT4 between treadmill running and skating cross-country skiing (Welde et al., 2003). Our findings indicate a diverse physiological response to exercise at AT4 intensity during roller skiing performed using the skating technique and treadmill running. This confirms that it is necessary to use field tests to determine training zones for skating roller skiing using the HR or V.

The study included only eight athletes and the authors realize that the quantity of the group can affect the power of the statistical conclusions. On the other hand practical implications from the study conducted on the selected, national team athletes can be useful for coaches, physiologists, and athletes for designing specific training programs.

\section{Conclusions}

The analysis confirmed that performing tests under field conditions is an optimal way to determine threshold values for roller skiing 
training. The study showed that it was possible to use threshold HR values obtained in tests completed using the classical or skating techniques to determine roller skiing training loads. The threshold HR values achieved during the laboratory (TR) test were found to be moderately useful for selecting loads only in classical technique roller skiing training. The results of the study indicate that there is a need to verify maximal treadmill running exertion variables using specific roller skiing tests.

\section{Acknowledgements}

This research project (RSA2 003 52) was funded by the Polish Ministry of Science and Higher Education from the budget for science for the years 2013-2016..

\section{References}

Czuba M, Maszczyk A, Gerasimuk D, Roczniok R, Fidos-Czuba O, Zając A, Gołaś A, Mostowik A, Langfort J. The Effects of Hypobaric Hypoxia on Erythropoiesis, Maximal Oxygen Uptake and Energy Cost of Exercise Under Normoxia in Elite Biathletes. J Sports Sci Med. 2014; 13(4): 912-20.

Doyon KH, Perrey S, Abe D, Hughson RL. Field testing of $\mathrm{VO}_{2 \text { peak }}$ in cross-country skiers with portable breathby-breath system. Can J Appl Physiol, 2001; 26(1): 1-11

Fabre N, Balestreri F, Leonardi A, Schena F. Racing performance and incremental double poling test on treadmill in elite female cross-country skiers. J Strength Cond Res, 2010; 24(2): 401-407

Fabre N, Passelergue P, Bouvard M, Perrey S. Comparison of heart rate deflection and ventilatory threshold during a field cross-country roller-skiing test. J Strength Cond Res, 2008; 22(6): 1977-84

Forbes SC, Chilibeck PD, Craven B, Bhambhani Y. Comparison of a double poling ergometer and field test for elite cross country sit skiers. N Am J Sports Phys Ther, 2010; 5(2): 40-6

Hoffman MD, Clifford PS, Watts PB, Drobish KM, Gibbons TP, Newbury VS, Sulentic JE, Mittelstadt SW, O'Hagan KP. Physiological comparison of uphill roller skiing: diagonal stride versus double pole. Med Sci Sports Exerc, 1994; 26(10): 1284-9

Hoffman MD, Clifford PS. Physiological Responses to Different Cross Country Skiing Techniques on Level Terrain. Med Sci Sports Exerc, 1990; 22(6): 841-48

Hoffman MD, Clifford PS, O'Hagan KP, Mittelstadt SW, Watts PB. Delta efficiency of uphill roller skiing with the double pole and diagonal stride techniques. Can J Appl Physiol, 1995; 20(4): 465-79

Holmberg HC, Lindinger S, Stöggl T, Björklund G, Müller E. Contribution of the Legs to Double-Poling Performance in Elite Cross-Country Skiers. Med Sci Sport Exerc, 2006; 38(10): 1853-60

Holmberg H, Rosdahl H. Lung function, arterial saturation and oxygen uptake in elite cross country skiers: influence of exercise mode. Scand J Med Sci Sports, 2007; 17(4): 437-444

Klusiewicz A, Faff J, Starczewska-Czapowska J. Prediction of maximal oxygen uptake from submaximal and maximal exercise on a ski ergometer. Biol Sport, 2011; 28: 31-5

Klusiewicz A, Cempa W. Verification of anaerobic threshold indicators for cross-country skiers in natural conditons. Polish J Sport Tour, 2011; 18(4): 300-3

LaRoche DP, Amann M, Rundell KW. Grade influences blood lactate kinetics during cross-country skiing. J Strength Cond Res, 2010; 24(1): 120-7

Larson AJ. Variations in heart rate at blood lactate threshold due to exercise mode in elite cross-country skiers. J Strength Cond Res, 2006; 20(4): 855-60

Larsson P, Olofsson P, Jakobsson E, Burlin L, Henriksson-Larsén K. Physiological predictors of performance in cross-country skiing from treadmill tests in male and female subjects. Scand J Med Sci Sports, 2002; 12(6): 347-53

Mahood NV, Kenefick RW, Kertzer R, Quinn TJ. Physiological determinants of cross-country ski racing performance. Med Sci Sports Exerc, 2001; 33(8): 1379-84

Macfarlane DJ, Wong P. Validity, reliability and stability of the portable Cortex Metamax 3B gas analysis 
system. Eur J Appl Physiol, 2012; 112: 2539-2547

Mikkola J, Laaksonen M, Holmberg H-C, Vesterinen V, Nummela A. Determinants of a Simulated CrossCountry Skiing Sprint Competition using V2 Skating Technique on Roller Skis. J Strength Cond Res, 2010; 24(4): 920-8

Mittelstadt SW, Hoffman MD, Watts PB, O'Hagan KP, Sulentic JE, Drobish KM, Gibbons TP, Newbury VS, Clifford PS. Lactate response to uphill roller skiing: diagonal stride versus double pole techniques. Med Sci Sports Exerc, 1995; 27(11): 1563-8

Myklebust H, Losnegard T, Hallén J. Differences in V1 and V2 ski skating techniques described by accelerometers. Scand J Med Sci Sports, 2014; 24(6): 882-93

Sandbakk Ø, Losnegard T, Skattebo Ø, Hegge AM, Tønnessen E, Kocbach J. Analysis of classical time-trial performance and technique-specific physiological determinants in elite female cross-country skiers. Front physiol, 2016a; 7: 326

Sandbakk Ø, Hegge AM, Losnegard T, Skattebo Ø, Tønnessen E, Holmberg HC. The physiological capacity of the world's highest ranked female cross-country skiers. Med Sci Sports Exerc, 2016b; 48(6): 1091-1100

Stöggl T, Lindinger S, Müller E. Reliability and validity of test concepts for the cross-country skiing sprint. Med Sci Sport Exerc, 2006; 38(3): 586-91

Tønnessen E, Haugen TA, Hem E, Leirstein S, Seiler S. Maximal aerobic capacity in the winter-Olympics endurance disciplines: Olympic-medal benchmarks for the time period 1990-2013. Int J Sports Physiol Perform, 2015; 10(7): 835-9

Vergès S, Flore P, Laplaud D, Guinot M, Favre-Juvin A. Laboratory running test vs. field roller skiing test in cross-country skiers: a longitudinal study. Int J Sports Med, 2006; 27(4): 307-13

Vogler AJ, Rice AJ, Gore CJ. Validity and reliability of the Cortex MetaMax3B portable metabolic system. J Sports Sci, 2010; 28: 733-742

Watts PB, Sulentic JE, Drobish KM, Gibbons TP, Newbury VS, Hoffman MD, Mittelstadt SW, O'Hagan KP, Clifford PS. Physiological responses to specific maximal exercise tests for cross-country skiing. Can J Appl Physiol, 1993; 18(4): 359-65

Welde B, Evertsen F, Von Heimburg E, Medbø JI. Energy cost of free technique and classical cross-country skiing at racing speeds. Med Sci Sports Exerc, 2003; 35(5): 818-25

Wisløff U, Helgerud J. Methods for evaluating peak oxygen uptake and anaerobic threshold in upper body of cross-country skiers. Med Sci Sports Exerc, 1998; 30(6): 963-70

Zeni AI, Hoffman MD, Clifford PS. Energy Expenditure With Indoor Exercise Machines. J Am Med Assoc, 1996; 275(18): 1424

\section{Corresponding author:}

\section{Michał Starczewski}

Institute of Sport - National Research Institute

Trylogii 2/16 Street,

01-982 Warsaw

Tel. (+4822) 569-99-70

E-mail: michal.starczewski@insp.waw.pl 